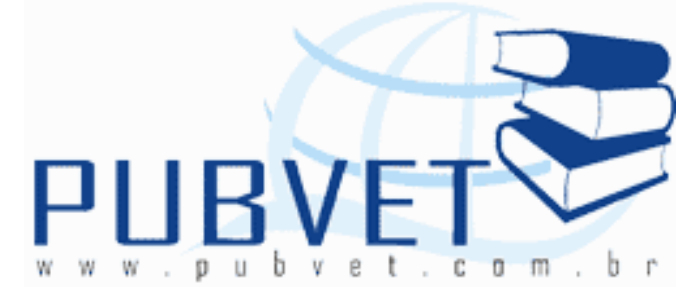

PUBVET, Publicações em Medicina Veterinária e Zootecnia.

\title{
Carcinoma de células escamosas em epitélio nasal de um hamster chinês - Relato de caso
}

\section{Mayara Caroline Rosolem ${ }^{1 *}$; Débora Cristina Romero ${ }^{2}$; Daniela Bernadete Rozza ${ }^{3}$; Natalia Cristina de Souza ${ }^{4}$; Daniel Castendo Simões ${ }^{5}$.}

1 Médica Veterinária mestranda em patologia veterinária pela Faculdade de Ciências Agrárias e Veterinárias da Universidade Estadual "Júlio de Mesquita Filho", Jaboticabal, SP.

2 Médica Veterinária mestranda do programa de pós-graduação em patologia experimental e comparada da Faculdade de Medicina Veterinária e Zootecnia (FMVZ) da Universidade de São Paulo (USP), São Paulo, SP.

${ }^{3}$ Médica Veterinária Doutora docente em patologia veterinária pela Faculdade de Medicina Veterinária de Araçatuba (FMVA) da Universidade Estadual Paulista "Júlio de Mesquita Filho" (UNESP), Araçatuba, SP.

${ }^{4}$ Médica Veterinária mestranda do programa de Ciência Animal da Faculdade de Medicina Veterinária de Araçatuba - FMVA (UNESP), Araçatuba, SP, Brasil.

${ }^{5}$ Médico Veterinário autônomo especialista em animais exóticos, Araçatuba, SP, Brasil.

* Endereço: Departamento de Patologia Veterinária, Faculdade de Ciências Agrárias e Veterinárias - UNESP, Via de Acesso Prof. Paulo Donato Castellane s/n, 14884-900 - Jaboticabal, SP. Email: mayara_rosolem@yahoo.com.br 


\title{
Resumo
}

O carcinoma de células escamosas (CCE) é uma neoplasia que acomete animais de companhia, de produção e exóticos, sendo muito comum em países de clima tropical como no Brasil, pois se desenvolve em áreas pouco pigmentadas, no epitélio escamoso estratificado e em superfícies mucosas expostas a ação ultravioleta. O CCE é bastante infiltrativo, porém raramente ocasiona metástases. Sua ocorrência no epitélio nasal é bastante relatada em felinos. O presente caso trata de um hamster chinês (Cricetulus griséus), fêmea, jovem, que desenvolveu um aumento de volume em espelho e plano nasal, e seu único sinal clínico era intenso prurido. O animal passou por procedimento cirúrgico para a realização de uma biopsia incisional, que foi encaminhada para o Serviço de Patologia Veterinária da UNESP, campus de Araçatuba (SP) para avaliação histopatológica. O material apresentou características compatíveis com carcinoma de células escamosas bem diferenciado.

Palavras-chave: neoplasia, pequenos roedores, carcinoma epidermóide, Cricetulus griséus

\section{Squamous cell carcinoma in nasal epithelium of a chinese hamster - Case report}

\begin{abstract}
The squamous cell carcinoma (SCC) is a neoplasm that affect pets, production animals and exotic animals, and it's very common in tropical countries like Brazil, once it develops a sparsely pigmented, stratified squamous epithelium and on surfaces mucosa exposed to ultraviolet action. The SCC is quite infiltrative but rarely causes metastases. Its occurrence in the nasal epithelium is widely reported in cats. This case is a chinese hamster (Cricetulus griséus), female, young, who developed a nasal nodule, and their only clinical sign was intense itching. The animal underwent surgery to perform an incisional biopsy, which was referred to the Veterinary Pathology Service of UNESP, campus of
\end{abstract}


Araçatuba (SP) for histopathological evaluation. The material showed features consistent with squamous cell carcinoma well differentiated.

Keywords: neoplasm, small rodents, epidermoide carcinoma, Cricetulus griséus.

\section{INTRODUÇÃO}

O carcinoma de células escamosas (CCE) é uma neoformação maligna de células epidérmicas, as quais se diferenciam em queratinócitos (GOLDSCHMIDT, 2002; SOUZA, 2005; SCOPEL, 2007), comum em países de clima tropical, como o Brasil. O CCE pode ser altamente invasivo e ocasionar metástases para linfonodos regionais, estrutura anexas, ossos e pulmões (GOLDSCHMIDT, 2002; KRAEGEL, 2004). O seu desenvolvimento pode estar associado a fatores genéticos, deficiências nutricionais, exposição excessiva ao sol, traumatismos freqüentes e má higiene (XAVIER, 2005). Acomete felinos, bovinos, caninos e eqüinos com bastante freqüência (SCOPEL, 2007), porém é pouco relatado em animais exóticos, como aves, répteis e pequenos roedores.

O objetivo deste trabalho é relatar o caso de um hamster chinês, fêmea, jovem que desenvolveu carcinoma de células escamosas nasal.

\section{RELATO DO CASO}

Foi encaminhado ao Serviço de Patologia Veterinária da Universidade Estadual "Júlio de Mesquita Filho" (UNESP) campus de Araçatuba (SP), um fragmento excisado para análise histopatológica proveniente de um hamster chinês, fêmea, com um ano e meio, que apresentou aumento de volume nasal com evolução rápida, de aproximadamente quinze dias (figuras 1 ). 0 animal tinha apenas prurido no local do aumento de volume, normodipsia e normorexia. Foi encaminhado para cirurgia onde foi realizada biopsia incisional do nódulo. A massa tinha odor pútrido e drenava conteúdo purulento. 0 
material coletado foi fixado em formol $10 \%$ e encaminhado para processamento histopatológico e corado com Hematoxilina e Eosina (HE).

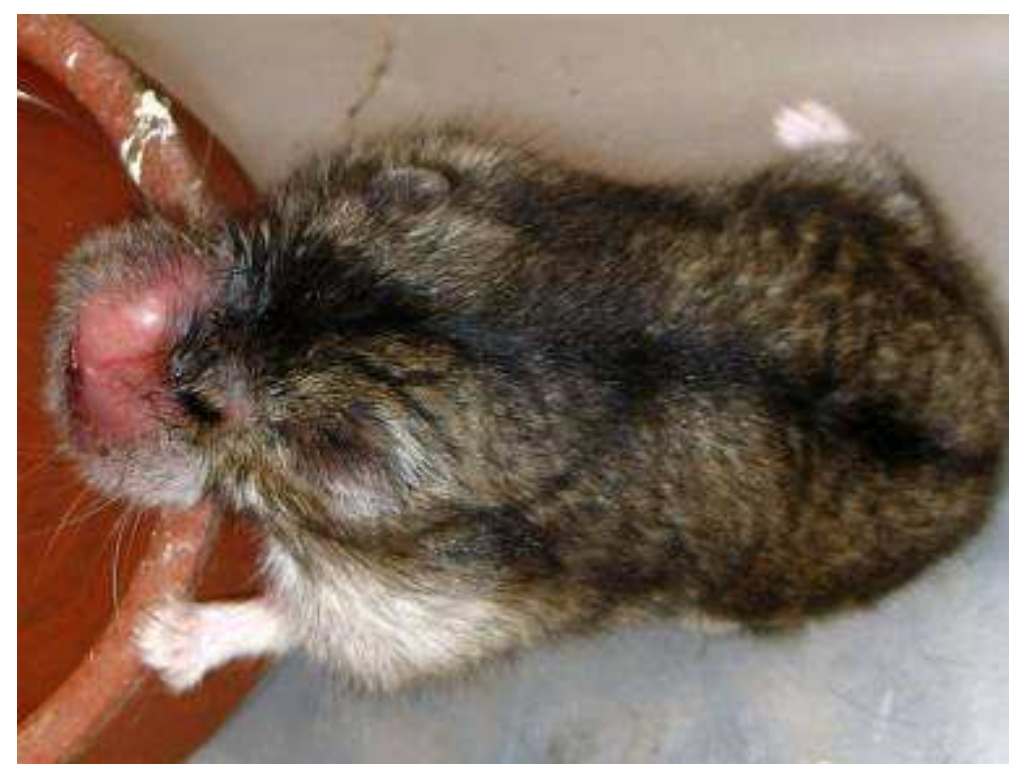

Figura 1. Fotografia do aumento de volume nasal (vista dorsal) (Fonte: Daniel Castendo Simões).

O fragmento tinha coloração rósea, consistência macia, superfície irregular e mediu aproximadamente $0,5 \times 0,5 \times 0,3 \mathrm{~cm}$. Microscopicamente foi observado hiperqueratose paraqueratótica moderada e proliferação das células do estrato espinhoso com projeção para a derme profunda (figura 2). As células do estrato espinhoso possuíam nucléolo evidente com mais de um núcleo e presença de grupos de isolados de células com centro queratinizado (figura 2), também conhecidas como pérolas de queratina, além de infiltrado inflamatório polimorfonuclear e mononuclear moderado. Na derme, havia vascularização evidente e edema moderado. O diagnóstico final foi de carcinoma de células escamosas queratinizado bem diferenciado. 


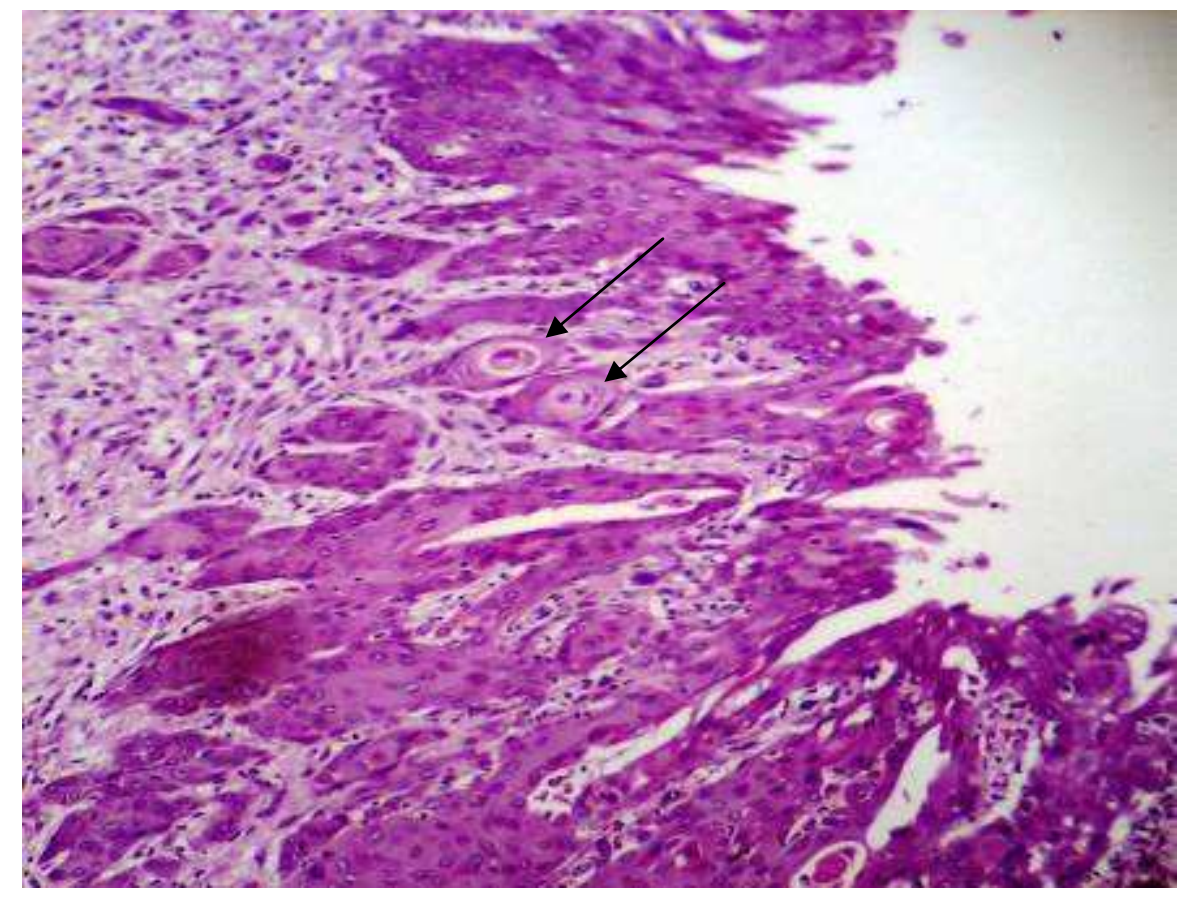

Figura 2. Fotomicrografia demonstrando a proliferação das células do estrato espinhoso com projeção para a derme profunda. Atente para a seta identificando a formação de pérolas de queratina (Fonte: Mayara Caroline Rosolem).

A literatura descreve que a ocorrência de neoplasias é comum em hamsters e que são mais freqüentes em machos do que em fêmeas (ALENCAR, 2003). O estímulo para a formação do carcinoma de células escamosas é bem conhecido em muitas espécies domésticas, e sabe-se que a influência principal está na exposição aos raios solares incididos constantemente sobre regiões glabras, áreas despigmentadas, levemente pigmentadas além do epitélio escamoso estratificado e de várias superfícies mucosas (JONES, 2000; KRAEGEL, 2004; KELLER, 2008). Estudos em ratos descrevem o desenvolvimento do CCE na mucosa da cavidade nasal após a emissão experimental de doses diferenciadas de formaldeído em vapor (SWENBERG, 1980). No presente caso, a causa do surgimento da neoplasia não ficou esclarecida.

No carcinoma de células escamosas a hiperplasia epitelial é evidente, sendo facilmente identificadas pérolas de queratina, células com morfologia alterada e infiltrado inflamatório linfoplasmocitário invadindo tanto tecido 
ROSOLEM, M.C. et al. Carcinoma de células escamosas em epitélio nasal de um hamster chinês

- Relato de caso. PUBVET, Londrina, V. 6, N. 19, Ed. 206, Art. 1379, 2012.

epitelial quanto o tecido conjuntivo. Na derme há aumento da vascularização do tecido conjuntivo, edema e presença de vasos em neoformação (OLIVEIRA, 2010). Os achados microscópicos foram compatíveis com os descritos na literatura.

O CCE é uma neoplasia que pode acometer animais domésticos e os animais exóticos, como foi relatado. No caso em questão, o diagnóstico histopatológico foi fundamental e suficiente para a deteç̧ão do tipo de enfermidade. Porém, devido ao escasso número de trabalhos na literatura sobre neoplasias em hamsters fica evidente a necessidade em se realizar mais pesquisas para haver melhor embasamento sobre o assunto.

\section{REFERÊNCIAS}

ALENCAR, N. X.; CORREIA, I. S.; ROMÃO, M. A. M. P.; VIEIRA, T. B.; FERREIRA, M. L. G.; TORTELLY, R. Osteossarcoma de tecidos moles em hamster chinês (Cricetulus griseus): relato de caso, São Pedro, SP, 2003. In: VII Congresso e XII Encontro da ABRAVAS, 2003. Anais... ABRAVAS, 2003, p86.

GOLDSCHIMIDT, M. H; HENDRICK, M. J. Tumors of the skin and soft tissues. In: MEUTEN, D. J. Tumors in Domestic Animals. 4.ed. Iowa: Iowa State Press, 2002. cap. 2, p. $45-117$.

JONES, T. C.; HUNT, R. D; KING, N. M. A pele e seus anexos. In: Patologia Veterinária. 6.ed. Barueri: Manole, 2000. cap 17, p. 831-886.

KRAEGEL, S. A.; MADEWELL, B. R. Tumores da Pele. In: ETTINGER, S. J.; FELDMANN, E. C. Tratado de Medicina Interna Veterinária. 5.ed. Rio de Janeiro: Guanabara/Koogan, 2004. cap. 99, p.555-557.

KELLER D., et al. Casuística de carcinoma epidermóide cutâneo em bovinos do campus palotina da UFPR. Acta Scientiae Veterinariae, Porto Alegre, v36, p. 155-159, 2008. Disponível em

< http://www.sumarios.org/sites/default/files/pdfs/art_779.pdf > Acesso em 25 de agosto de 2011.

OLIVEIRA, M. A.; NUNES, M. B.; XAVIER, L. L.; SOUZA, F. L.;LOPES, M. A. Descrição histológica qualitativa de tumores em bolsa jugal de hamster sírio dourado. Porto Alegre, RS, 2010. Anais XI Salão de Iniciação Científica - PUCRS, agosto de 2010. p. 279-280.

SCOPEL, D.; SPADER M. B.; GUIM, T. N.; DANIELI, V. M.; FERNANDES, C. G. Estudo retrospectivo da casuística de carcinoma de células escamosas em felinos, bovinos, caninos, eqüinos e ovinos entre os anos de 2002 e 2006 no Lrd/Ufpel. In: CIC (Congresso de Iniciação Científica de Pesquisa e Responsabilidade Ambiental) 16, 2007, Pelotas. Anais co XVI CIC. Pelotas: UFPEL, 2007.p.4. 
SWENBERG, J. A.; KERNS, D. K.; MITCHELL, R. I.; GRALIA, E. J.; PAVKOV, K. L. Induction of squamous cell Carcinomas of the Rat Nasal Cavity by Inhalation exposure to Formaldehyde vapor. Cancer Research, v.40, 3398-3402, September 1980. Disponível em, <http://cancerres.aacrjournals.org/content/40/9/3398> Acesso em 15 de agosto de 2011.

XAVIER, S.D.; BUSSOLOTI, I. F.; LANCELLOTTI, C.L.P. Prevalência de achados sugestivos de papilomavírus humano (HPV) em biópsias de carcinoma espinocelular de cavidade oral e orofaringe: estudo preliminar. Revista Brasileira de Otorrinolaringologia, São Paulo v.71, n.4, p.510-514, 2005. Disponível em <http://www.scielo.br/pdf/rboto/v71n4/a19v71n4.pdf > Acesso em 13 de agosto de 2011. 